\title{
Management of sepsis
}

\author{
lain Mackenzie, ${ }^{1}$ Andrew Lever $^{2}$
}

John Farman Intensive Care Unit, Box 17, Addenbrooke's Hospital, Cambridge CB2 $2 \mathrm{QQ}$

${ }^{2}$ Department of Medicine,

University of Cambridge,

Cambridge

Correspondence to: I Mackenzie iain@number2.demon.co.uk

BMJ 2007;335:929-32

doi:10.1136/bmj.39346.696620.AE
This is the second of two reviews - the first discussed the definition, epidemiology, and diagnosis of sepsis, whereas this one focuses on management and outcome. Management of sepsis can conveniently be divided into general supportive measures and specific treatment.

\section{What are the general supportive measures?}

Circulatory compromise arises from the combination of vasodilatation, capillary leak, and reduced myocardial contractility, and needs early correction. Whether crystalloids or colloids are better for volume resuscitation remains unresolved. Few people now use human albumin after a controversial meta-analysis concluded that albumin was associated with a $6 \%$ excess mortality. ${ }^{1}$ A subsequent randomised controlled trial found no difference in any of the outcome measures examined, including mortality. ${ }^{2}$

Another question is how to gauge the adequacy of fluid resuscitation. The pulmonary artery catheter has not been shown to be associated with either harm or benefit, ${ }^{34}$ and its use is declining. Clinical end points (box 1) remain useful, although some centres are also using oesophageal Doppler or pulse contour analysis. These methods provide information on the effect of fluid loading on cardiac output and stroke volume. In ventilated patients, variation in stroke volume can be used as an index of preload.

Catecholamines are needed when fluids are insufficient to restore adequate tissue perfusion. The quality of evidence on which to base the choice of agents is poor. Currently, either noradrenaline (norepinephrine) or dopamine is recommended as first line agent. Noradrenaline increases the blood pressure more rapidly and reliably than dopamine and improves renal function, but it produces only a modest rise in cardiac output. Its effects on the liver and gastrointestinal mucosa are unpredictable. Dopamine, on the other hand, despite increasing splanchnic blood flow at low doses, does not increase oxygen consumption in the gut or improve hepatic function. Moreover, unease is growing about its negative effects. These include reduction of gut motility, hypoprolactinaemia mediated immunosuppression, reduced anabolism, and impaired thyroid function. In a recent observational study, dopamine was associated with an increased risk of death in hospital. ${ }^{5}$ At high doses, dopamine may precipitate supraventricular arrhythmias. Adrenaline (epinephrine) is now rarely used as a single agent, if at all. It causes a fall in splanchnic perfusion and, in some cases, a lactic acidosis. In the future, an increased understanding of the effects of adrenoreceptor up regulation and down regulation, adrenoreceptor gene polymorphism, and free radical alterations to adrenoreceptor activation may lead to better use of catecholamines.

The role of non-catecholamine drugs, such as vasopressin, levosimendan, methylene blue, and the phosphodiesterase inhibitors, to support the circulation in sepsis remains to be clarified. Timeliness of the intervention and attention to subtle signs of persisting tissue hypoperfusion are important. Survival is increased when volume loading to standard end points (box 2) is supplemented, where necessary, by blood, catecholamines, and even mechanical ventilation. ${ }^{6}$

Many patients with severe sepsis, even without pulmonary sepsis, need respiratory support because of the combined effects of increased ventilatory demand, hypoxaemia, and respiratory muscle dysfunction. ${ }^{7}$ Some patients develop the acute respiratory distress syndrome. The duration of mechanical ventilation can be reduced by daily interruptions of sedation, ${ }^{8}$ and a $9 \%$ increase in survival has been achieved in patients with acute lung injury or acute respiratory distress syndrome by using low tidal volumes ( $6 \mathrm{ml} / \mathrm{kg}$ ideal body weight). ${ }^{9}$

Renal failure occurs in 20-50\% of patients, depending on severity. Some evidence shows that high volume haemofiltration temporarily reduces the need for vasopressors, ${ }^{10}$ but whether this translates into any long term advantages, in terms of either renal function or survival, has not been proved.

Nutrition is another area in which high quality data are scarce, particularly among non-surgical patients. In general, early enteral nutrition is recommended, ${ }^{11}$ but this was associated with increased morbidity in the only study in non-surgical patients. ${ }^{12}$ Furthermore, supplements designed to boost the immune system,

Box 1 Clinical and functional end points for titration of fluid resuscitation

- Sustained increase in blood pressure

- Sustained increase in central venous pressure

- Fall in heart rate

- Increased urine output

- Increase in mixed venous saturation

- Fall in base deficit

- Fall in blood lactate concentration 
Box $2 \mid$ Resuscitation end points in the study by Rivers and colleagues ${ }^{6}$

- Central venous pressure of 8-12 mm Hg

- Mean arterial pressure $\geq 65 \mathrm{~mm} \mathrm{Hg}$

- Urine output $\geq 0.5 \mathrm{ml} / \mathrm{kg} / \mathrm{hr}$

- Central venous oxygen saturation $\geq 70 \%$

such as 1-arginine and omega-3 fatty acids, actually increase mortality in patients with severe sepsis. ${ }^{13}$ Interpretation of these studies is confounded by the effect of hyperglycaemia. The combination of glycogenolysis and insulin resistance means that hyperglycaemia is common in patients with sepsis and is associated with a poorer outcome. ${ }^{14}$ Tight glycaemic control has been shown to reduce morbidity and mortality in a prospective randomised controlled trial in surgical patients. ${ }^{15}$ A similar study in non-surgical patients resulted in a reduction only in morbidity. ${ }^{16}$ We clearly need a more definitive understanding of the impact of hyperglycaemia and insulin treatment in patients with severe sepsis, which will hopefully be provided by an ongoing randomised controlled trial. ${ }^{17}$

\section{What specific treatments are available? Antimicrobials}

First and foremost among specific treatments are prompt appropriate empirical antimicrobials. Treatment within four hours of admission reduces mortality and length of stay. ${ }^{18}$ Delay in hypotensive patients increases mortality by $7.6 \%$ an hour. ${ }^{19}$ Since the late $1980 \mathrm{~s}$, Gram positive organisms have replaced Gram negative ones as the most common bacteria causing sepsis. Retrospectively, around $20 \%$ of infections originate from each of respiratory, intra-abdominal, and urinary tract sources. However, at presentation, the source of infection is often unknown. Antibiotic treatment must be guided by the patient's susceptibility group (table) and local knowledge of bacterial resistance. Broad spectrum $\beta$ lactam antibiotics would be the usual first line agent. If methicillin resistant Staphylococcus aureus is a risk, empirical vancomycin should be added. In the presence of risk factors for fungal infection, an antifungal agent may be prescribed initially or within 48 hours if no improvement occurs; decisions are guided by clinical

\begin{tabular}{ll}
\hline $\begin{array}{l}\text { Patients' susceptibilities and implications for treatment } \\
\text { Susceptibility }\end{array}$ & $\begin{array}{l}\text { Consider } \\
\text { In hospital or other institution }\end{array}$ \\
$\begin{array}{ll}\text { Resistant organisms, especially methicillin resistant Staphylococcus } \\
\text { aureus (MRSA) and extended spectrum } \beta \text { lactamase producing Gram } \\
\text { negative enteric organisms }\end{array}$ \\
\hline Splenectomy & Capsulated bacteria, especially Streptococcus pneumoniae \\
\hline School, university, or military & Neisseria meningitidis \\
\hline Intravascular catheter & Staphylococci \\
\hline Intubation and ventilation & Gram negative enteric organisms, pseudomonads, MRSA, Candida \\
\hline Pharmacologically & Pneumocystis jirovecii, cytomegalovirus, Candida spp, Arpergillus spp, \\
immunosuppressed & Nocardia spp \\
\hline Foreign travel & Malaria, legionella \\
\hline Potential exposure to rat urine & Leptospirosis \\
\hline Very young or very old & Listeria monocytogenes \\
\hline
\end{tabular}

judgment and the severity of the condition, ideally in consultation with infectious disease or microbiology colleagues. The importance of wide cover is illustrated by the much poorer prognosis in patients in whom the first line drugs are ineffective. ${ }^{20}$ If strong clues to the source of infection exist, targeted narrower spectrum treatment is probably justified.

Protein $\mathrm{C}$ is synthesised by the liver and activated by thrombomodulin-bound thrombin, acquiring antiinflammatory, antithrombotic, and anticoagulant effects. A recombinant human protein (drotrecogin alfa (activated)) was evaluated in a large prospective randomised controlled trial. ${ }^{21}$ It was, somewhat controversially, approved in November 2001 by the US Food and Drug Administration on the basis of a reduction in the absolute risk of death of $6.1 \%(\mathrm{P}=0.005)$ and subgroup analysis of predefined high risk patients (defined as an acute physiology and chronic health evaluation II (APACHE II) score of $\geq 25$ ). In the intervening time two further randomised controlled trials have been published, one in children and the other in adults at low risk of death. ${ }^{223}$ Both were stopped early on grounds of inefficacy. In addition, the calculated risk of serious haemorrhage from drotrecogin alfa (activated) has increased progressively with accumulating clinical experience. Overall, whether the risks of drotrecogin alfa (activated) outweigh the benefits is now far from clear, even in patients with a high risk of death.

\section{Corticosteroids}

Deficiency of adrenal steroid production in severe sepsis was originally described as acute haemorrhagic necrosis of the adrenal glands precipitating addisonian crisis and death - the Waterhouse-Friderichsen syndrome. High dose corticosteroid treatment in severe sepsis was initially investigated as an anti-inflammatory treatment and found to be of no benefit. Attention has now returned to the problem of adrenal insufficiency in severe sepsis. Complete adrenal failure is rare, but relative adrenal insufficiency is much more common, although the incidence depends on the definition used. In one study, for example, which defined adrenal insufficiency as a cortisol increment of $\leq 248 \mathrm{nmol} / \mathrm{l}(9 \mu \mathrm{g} / \mathrm{dl}) 30-60$ minutes after $0.25 \mathrm{mg}$ of tetracosactrin, $54 \%$ of the patients with septic shock met the criteria. ${ }^{24}$ Two recent meta-analyses suggest that low dose hydrocortisone for five to 11 days in unselected patients with severe sepsis or septic shock significantly reduces both the duration of shock and inhospital mortality, without incurring additional complications. The positive effect of low dose steroid replacement treatment may be even greater if it is restricted to patients selected on the basis of proved adrenal insufficiency.

\section{Immunoglobulins and statins}

Other therapeutic approaches deserve further investigation. Of these, intravenous immunoglobulin and statins are nearest to clinical evaluation. Intravenous immunoglobulin is not without adverse effects, which vary from hypotensive reactions to aseptic meningitis. Most of the infused antibody will not be specific for the organism 


\section{SOURCES AND SELECTION CRITERIA}

We searched Medline with the search phrase "((sepsis[title] OR septic*[title]) NOT (infant* OR neonat* OR child*))" and restricted the search to articles published in English in the previous three years. We individually reviewed the titles of the 2620 articles retrieved to identify major themes. Where necessary, we made additional searches based on key words or concepts that had been identified in the initial search. We also searched the Cochrane Library and Clinical Evidence. We then each used this information supplemented by knowledge and experience from our own field to prepare a brief review of the sections with which we were most familiar

responsible for the infection. The hope that polyclonal antiendotoxin antibody cross reactivity will be of use persists, despite the convincing failure of monoclonal antiendotoxin antibody to influence outcome. Several trials and analyses of these trials are in the literature, and both bodies of work have examples of conflicting or ambiguous results. One meta-analysis that separated trials into high and low quality studies showed no benefits in the high quality studies but a relative risk of death of 0.61 in the low quality studies. The authors conclude that the evidence from the high quality studies is enough to dissuade them from using intravenous immunoglobulin in sepsis except in randomised trials. ${ }^{25} \mathrm{~A}$ larger review shows a relative risk of death of 0.91 in patients treated with polyclonal immunoglobulin. It concludes that polyclonal immunoglobulin $\mathrm{G}$ is promising but unproved. ${ }^{26}$

Statins are lipid lowering agents that act by inhibiting hepatic hydroxymethyl glutaryl coenzyme A reductase and are in widespread use for the prevention of coronary artery disease. Recognised as having anti-inflammatory properties, among many others, they have subsequently been shown to reduce the risk of developing sepsis, as well as the severity of and mortality from sepsis. Intriguingly, in a murine model of sepsis, treatment with statins instituted after the septic insult was able to prolong survival. ${ }^{27}$ Whether this effect could be replicated in patients is not clear.

\section{HMGB-1}

Among the inflammatory response mediators being targeted, high mobility group box 1 (HMGB-1) protein is of particular interest. HMGB-1 is an essential nuclear DNA binding protein that acts as an "architectural" transcriptional cofactor. Secreted HMGB-1 is a potent inflammatory mediator that appears late in the septic cascade. It has several actions, including increased expression of a distinct gene set including those for inflammatory cytokines. Injection of recombinant HMGB-1 replicates the clinical features of sepsis in mice, including multiple organ failure and death Conversely, antagonism of HMGB-1 in a rodent model of sepsis reduces organ damage and improves survival, even when treatment is started after the septic insult. Circulating concentrations of HMGB-1 are significantly increased in patients with severe infection and are lower in survivors than in non-survivors. ${ }^{28}$ Two very different interventions seem to usefully reduce release of HMGB-1. Firstly, ethyl pyruvate, a stable aliphatic ester of pyruvate, effects a dose dependent reduction in HMGB-1 concentration and reduces mortality in a

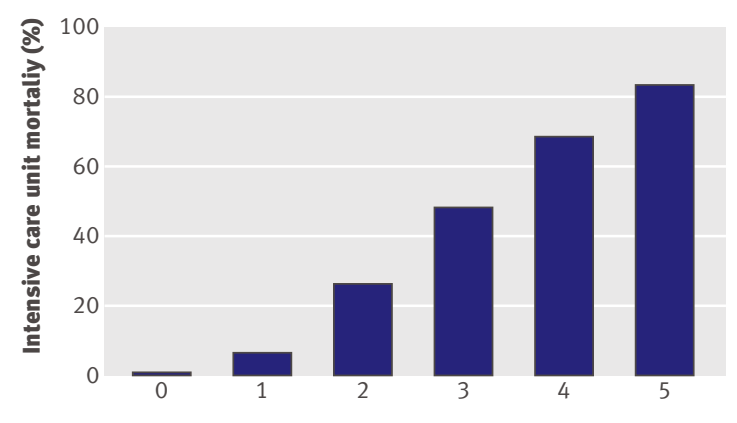

No of failed organ systems

Relation between organ failure and intensive care unit outcome ou $^{31}$

murine model of indolent sepsis, even when given 24 hours after its onset. Ethyl pyruvate has already been investigated in phase 1 studies in man. Secondly, release is inhibited by agonists of the $\alpha 7$-nicotinic acetylcholine receptor expressed on the surface of human macrophages, whose natural ligand is acetylcholine released from nerve endings of the common coeliac branch of the vagus nerve within the spleen. This represents the effector arm of the "cholinergic anti-inflammatory pathway" and suggests intriguing therapeutic possibilities not only for pharmacological intervention using synthetic agonists but perhaps even for psychological and biofeedback manipulation of the inflammatory response.

\section{Multiple system organ failure and outcome}

Until the progression of the septic process has been brought under control with effective antimicrobials and, where necessary, surgery, patients are at risk of sequential organ failure (box 3). Mortality is strongly associated with the number of failed organs (figure). In the medium term and long term, the only organs that show obvious residual dysfunction are the kidneys. Of patients who develop acute renal failure, less than $20 \%$ need dialysis on discharge from hospital and more than $50 \%$ of these eventually become independent of dialysis. The literature describing the medium term and long term quality of life of survivors is sparse, includes few patients, and is generally of poor quality. In one study, almost $50 \%$ of survivors had failed to return to their usual activities six months after discharge from intensive care $^{29}$; even after 16 months, survivors were significantly less well than age matched controls. ${ }^{30}$

Box 3 |Common sequence of organ failure

Primary involvement

- Heart and circulation

Secondary involvement

- Kidneys

- Respiratory system

- Brain (often overlooked in younger patients)

Tertiary involvement

- Liver

- Haemostatic system 


\section{ADDITIONAL EDUCATIONAL RESOURCES}

European Society of Intensive Care Medicine (www.esicm.org)_Access to a range of guidelines, including the surviving sepsis campaign guidelines for the management of severe sepsis and septic shock

Society of Critical Care Medicine (www.sccm.org/SCCM/LearnICU/Quick+Links)— Access to a range of guidelines

American Thoracic Society (www.thoracic.org/sections/clinical-information/criticalcare/evidence-based-critical-care)—Useful information and access to guidelines

Information resources for patients

Meningitis Research Foundation (www.meningitis.org)_A UK based charity aimed at supporting research into meningitis and septicaemia, as well as providing education and awareness to reduce death and disability and give support to people affected Intensive Care Society (www.ics.ac.uk/patrel/patrel.asp)_For information about many aspects of intensive care that might be of interest to the friends and family of a patient with septicaemia

Society of Critical Care Medicine (www.myicucare.org/sccm/MylCUCare)—For information that is relevant to patients in the United States

\section{Conclusion}

The severity of sepsis, its heterogeneous causation, the urgency of treatment, and the high mortality make it a problem area for randomised placebo controlled clinical trials, although the area is in striking need of these, particularly with newer biological therapeutic agents appearing. Meta-analysis and clinical experience are left to guide us through current therapeutic controversies. All of these, however, are of little use without a high index of clinical suspicion and the ability to act without delay when sepsis threatens.

Contributors: Each author researched and drafted the sections with which they were most familiar. IM combined the separate contributions. Both authors contributed to and approved the submitted and final versions of the manuscript. IM is the guarantor.

Competing interests: None declared.

Provenance and peer review: Commissioned; externally peer reviewed.

1 Cochrane Injuries Group Albumin Reviewers. Human albumin administration in critically ill patients: systematic review of randomised controlled trials. BMJ 1998;317:235-40.

2 Finfer S, Bellomo R, Boyce N, French J, Myburgh J, Norton R. A comparison of albumin and saline for fluid resuscitation in the intensive care unit. N Engl J Med 2004;350:2247-56.

3 Harvey S, Harrison DA, Singer M, Ashcroft J, Jones CM, Elbourne D, et al. Assessment of the clinical effectiveness of pulmonary artery catheters in management of patients in intensive care (PAC-Man): a randomised controlled trial. Lancet 2005;366:472-7.

4 Wheeler AP, Bernard GR, Thompson BT, Schoenfeld D, Wiedemann HP, deBoisblanc B, et al. Pulmonary-artery versus central venous catheter to guide treatment of acute lung injury. $N$ Engl J Med 2006;354:2213-24.

5 Sakr Y, Reinhart K, Vincent JL, Sprung CL, Moreno R, Ranieri VM, et al. Does dopamine administration in shock influence outcome? Results of the sepsis occurrence in acutely ill patients (SOAP) study. Crit Care Med 2006;34:589-97.

6 Rivers E, Nguyen B, Havstad S, Ressler J, Muzzin A, Knoblich B, et al. Early goal-directed therapy in the treatment of severe sepsis and septic shock. N Engl J Med 2001;345:1368-77.

\section{SUMMARY POINTS}

A favourable outcome depends on early, aggressive, treatment

Antimicrobial treatment must take into account both patient susceptibilities and local resistance patterns; advice from infectious disease or microbiology colleagues is often helpful

Volume resuscitation and cardiovascular support should be titrated to simple clinical end points

Subtle signs of organ hypoperfusion should be sought in physically robust patients The role of activated protein $\mathrm{C}$ and low dose steroids remains to be clarified
7 Lanone S, Taille C, Boczkowski J, Aubier M. Diaphragmatic fatigue during sepsis and septic shock. Intensive Care Med 2005;31:1611-7.

8 Kress JP, Pohlman AS, O'Connor MF, Hall JB. Daily interruption of sedative infusions in critically ill patients undergoing mechanical ventilation. N Engl J Med 2000;342:1471-7.

9 Acute Respiratory Distress Syndrome Network. Ventilation with lower tidal volumes as compared with traditional tidal volumes for acute lung injury and the acute respiratory distress syndrome. N Engl J Med 2000;342:1301-8.

10 Venkataraman R, Subramanian S, Kellum JA. Clinical review: extracorporeal blood purification in severe sepsis. Crit Care 2003;7:139-45.

11 Kreymann KG, Berger MM, Deutz NE, Hiesmayr M, Jolliet $P$, Kazandjiev G, et al. ESPEN guidelines on enteral nutrition: intensive care. Clin Nutr 2006;25:210-23.

12 Ibrahim EH, Mehringer L, Prentice D, Sherman G, Schaiff R, Fraser V, et al. Early versus late enteral feeding of mechanically ventilated patients: results of a clinical trial. JPEN J Parenter Enteral Nutr 2002;26:174-81.

13 Bertolini G, lapichino G, Radrizzani D, Facchini R, Simini B, Bruzzone $P$, et al. Early enteral immunonutrition in patients with severe sepsis: results of an interim analysis of a randomized multicentre clinical trial. Intensive Care Med 2003;29:834-40.

14 Krinsley JS. Association between hyperglycaemia and increased hospital mortality in a heterogeneous population of critically ill patients. Mayo Clin Proc 2003;78:1471-8.

15 Van den Berghe G, Wouters P, Weekers F, Verwaest C, Bruyninckx F, Schetz $M$, et al. Intensive insulin therapy in critically ill patients. $N$ Engl J Med 2001;345:1359-67.

16 Van den Berghe G, Wilmer A, Hermans G, Meersseman W, Wouters PJ, Milants I, et al. Intensive insulin therapy in the medical ICU. N Engl J Med 2006;354:449-61.

17 The George Institute. Normoglycaemia in intensive care evaluation and survival using glucose algorithm regulation-NICE-SUGAR. 2005. www.thegeorgeinstitute.org/research/critical-care-\&-trauma/ research/normoglycaemia-in-intensive-care-evaluation-nice.cfm (accessed 12 Oct 2007).

18 Houck PM, Bratzler DW, Nsa W, Ma A, Bartlett JG. Timing of antibiotic administration and outcomes for Medicare patients hospitalized with community-acquired pneumonia. Arch Intern Med 2004;164:637-44.

19 Kumar A, Roberts D, Wood KE, Light B, Parrillo JE, Sharma S, et al. Duration of hypotension before initiation of effective antimicrobial therapy is the critical determinant of survival in human septic shock. Crit Care Med 2006;34:1589-96.

20 Harbarth S, Garbino J, Pugin J, Romand JA, Lew D, Pittet D. Inappropriate initial antimicrobial therapy and its effect on survival in a clinical trial of immunomodulating therapy for severe sepsis. $\mathrm{Am}$ Med 2003;115:529-35.

21 Bernard GR, Vincent J-L, Laterre P-F, LaRosa SP, Dhainaut J-F, Lopez-Rodriguez A, et al. Efficacy and safety of recombinant human activated protein $\mathrm{C}$ for severe sepsis. N Engl J Med 2001;344:699-709.

22 Nadel S, Goldstein B, Williams MD, Dalton H, Peters M, Macias WL, et al. Drotrecogin alfa (activated) in children with severe sepsis: a multicentre phase III randomised controlled trial. Lancet 2007;369:836-43.

23 Abraham E, Laterre PF, Garg R, Levy H, Talwar D, Trzaskoma BL, et al. Drotrecogin alfa (activated) for adults with severe sepsis and a low risk of death. N Engl J Med 2005;353:1332-41.

24 Annane D, Sebille V, Troche G, Raphael JC, Gajdos P, Bellissant E. A 3 level prognostic classification in septic shock based on cortisol levels and cortisol response to corticotropin. JAMA 2000;283:1038-45.

25 Pildal J, Gotzsche PC. Polyclonal immunoglobulin for treatment of bacterial sepsis: a systematic review. Clin Infect Dis 2004;39:38-46

26 Alejandria MM, Lansang MA, Dans LF, Mantaring JB. Intravenous immunoglobulin for treating sepsis and septic shock. Cochrane Database Syst Rev 2002;(1):CD001090.

27 Merx MW, Liehn EA, Graf J, van de Sandt A, Schaltenbrand M, Schrader J, et al. Statin treatment after onset of sepsis in a murine model improves survival. Circulation 2005;112:117-24.

28 Angus DC, Yang L, Kong L, Kellum JA, Delude RL, Tracey KJ, et al. Circulating high-mobility group box 1 (HMGB1) concentrations are elevated in both uncomplicated pneumonia and pneumonia with severe sepsis. Crit Care Med 2007;35:1061-7.

29 Granja C, Dias C, Costa-Pereira A, Sarmento A. Quality of life of survivors from severe sepsis and septic shock may be similar to that of others who survive critical illness. Crit Care 2004;8:R91-8.

30 Heyland DK, Hopman W, Coo H, Tranmer J, McColl MA. Long-term health-related quality of life in survivors of sepsis. Short form 36: a valid and reliable measure of health-related quality of life. Crit Care Med 2000;28:3599-605.

31 Marshall JC, Cook DJ, Christou NV, Bernard GR, Sprung CL, Sibbald WJ. Multiple organ dysfunction score: a reliable descriptor of a complex clinical outcome. Crit Care Med 1995;23:1638-52. 